\title{
Influence of Passenger Comfort Requirements on the Interior Layout of Long-Haul Aircraft
}

\author{
Mikhail Yu. Kuprikov ${ }^{1, *}$, Alexander A. Orekhov ${ }^{2}$, Yelizaveta D. Shulga ${ }^{1}$, Yan Naing Min ${ }^{3}$ \\ ${ }^{1}$ Department of Engineering Graphics, Moscow Aviation Institute (National Research University), Moscow, 125993, \\ Russian Federation \\ ${ }^{2}$ Institute of General Engineering Education, Moscow Aviation Institute (National Research University), Moscow, 125993, \\ Russian Federation \\ ${ }^{3}$ Department of Mathematics, Defence Services Academy (D.S.A), Pyin Oo Lwin, 05081, Myanmar
}

Received November 27, 2020; Revised December 24, 2020; Accepted February 2, 2021

\section{Cite This Paper in the following Citation Styles}

(a): [1] Mikhail Yu. Kuprikov, Alexander A. Orekhov, Yelizaveta D. Shulga, Yan Naing Min, "Influence of Passenger Comfort Requirements on the Interior Layout of Long-Haul Aircraft," Civil Engineering and Architecture, Vol. 9, No. 3, pp. 820-827, 2021. DOI: 10.13189/cea.2021.090323.

(b): Mikhail Yu. Kuprikov, Alexander A. Orekhov, Yelizaveta D. Shulga, Yan Naing Min (2021). Influence of Passenger Comfort Requirements on the Interior Layout of Long-Haul Aircraft. Civil Engineering and Architecture, 9(3), 820-827. DOI: 10.13189/cea.2021.090323.

Copyright $\mathrm{C} 2021$ by authors, all rights reserved. Authors agree that this article remains permanently open access under the terms of the Creative Commons Attribution License 4.0 International License

\begin{abstract}
The plane has become a convenient method of transportation. The main idea of aviation in the $21 \mathrm{st}$ century is the safety of passengers and crew, but the human is always inclined towards comfort. The structural and parametric analysis of the long-haul aircraft development made it possible to form the concept of the fuselage layout with capsule accommodation of passengers. By adding the third axis to the dimension of the aircraft expressed in take-off mass, it clearly showed the ultimate dimension of the aircraft, expressed by modern infrastructural constraints. The histogram of the distribution of flights between the largest airports in the world that can operate with long-haul aircraft was showed. The distribution of large airports was characterised by the demographic factor. The proposed variant of the capsule accommodation, designed for the Boeing 777-200LR, can be installed in other passenger airliners with a ceiling height of at least 2.1 $\mathrm{m}$. Analysis of alternative options for the layout of the passenger compartment allows us to state: with a flight range of more than 8 hours, the flight is comfortable only in business or first classes. The proposed two-story capsule placement allows providing the layout with first-class seats in a given cabin.
\end{abstract}

Keywords Fuselage, Moment of Inertia, Square-Cube Law, Load-Range Diagram, Capsule

\section{Introduction}

The slogan "to fly the fastest and farthest" has received an economic connotation in the 21 st century. It is necessary to fly wherever it is necessary, and so it should be fast, cheap and most importantly comfortable [1-15]. This is the nature of today's demands. Let us try to interpret these requirements into the language of numbers, depending on the flight range of an aircraft. The development of long-haul aircraft of the Boeing and Airbus families (Figure 1), covers all the many park problems that exist in the World. An evolutionary attempt to overtake these manufacturers is possible only in a situation of using competencies that give a qualitative gain [15-20].

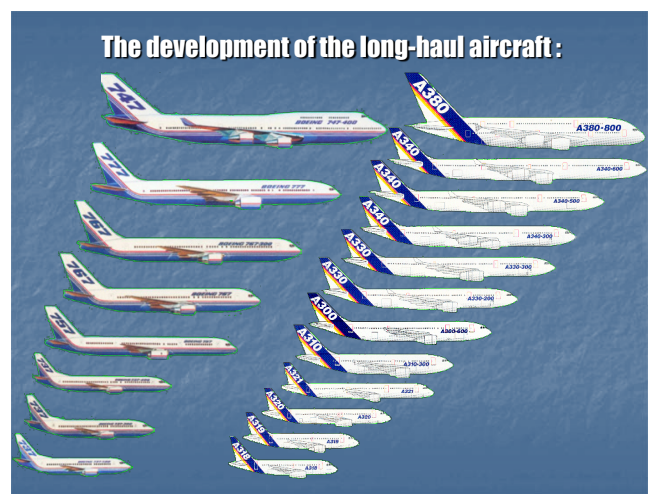

Figure 1. Development of Long-Haul Aircraft of the Boeing and Airbus Families 
The main idea of aviation in the 21 st century is undoubtedly the safety of flight [19-30]. The economic design of aircraft will force the manufacturer to move away from the external appearance parameters of aviation systems to the internal redesign of already known and well-proven types of aircraft [1-4]. All other things being equal, the economic perfection of the aircraft can be identified on the Pareto-optimal set in the coordinates of the load-range diagram, where the cruising range is determined by the Breguet formula, expressed through the relative fuel mass $\overline{\mathrm{m}}_{\mathrm{T}}$ (Eq. 1):

$$
\mathrm{L}=\mathrm{K} \text { a } \mathrm{M} / \mathrm{C}_{\mathrm{p}} \ln \left(1 /\left(1-\overline{\mathrm{m}}_{\mathrm{T}}\right),\right.
$$

where: $L$ - estimated cruising flight range; $C_{p}-$ specific fuel consumption; $K$ - aerodynamic quality; $a$ - the speed of sound; $M$ - flight speed.

By adding the third axis to the dimension of the aircraft, for example, expressed in take-off mass, we can clearly show the ultimate dimension of the aircraft, expressed by modern infrastructural constraints (Fig. 2). For example, at point $\mathrm{A}$, the aircraft design as a transport system degenerates. Splicing of points of the estimated flight range $\mathrm{P}$, which is due to the limitation of the target load in the volume of the passenger compartment, and $\mathrm{T}-$ the maximum flight range with the target load, due to the volume of fuel tanks.
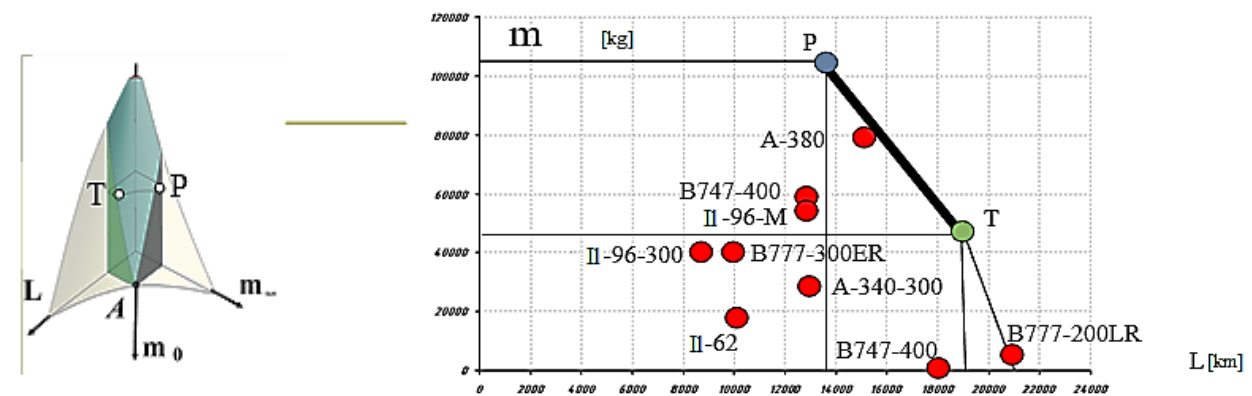

Figure 2. Long-Haul Aircraft Cargo-Range Diagram

That is, in fact, the plane begins to carry itself with zero payload weight return. An interesting example is the New York - Singapore route of the Singapore Airlines SQ 21 with a length of $15.345 \mathrm{~km}$. The Airbus 340-500 is in the air for 18 hours and 50 minutes. The layout of the cabin is noteworthy: only 98 business-class seats $(250$ seats in an economy class layout), that is, the minimum layout density for a given volume of the passenger compartment. For many years, since June 29, 2004, this flight was the longest in the world. But it was cancelled in October 2012 for purely economic reasons. The Figure 3 shows a histogram of the distribution of flights between the largest airports in the world that can operate with long-haul aircraft (B747, A-380, B777, A-340). These airports are represented by red dots on the world map below (Fig. $3)$.

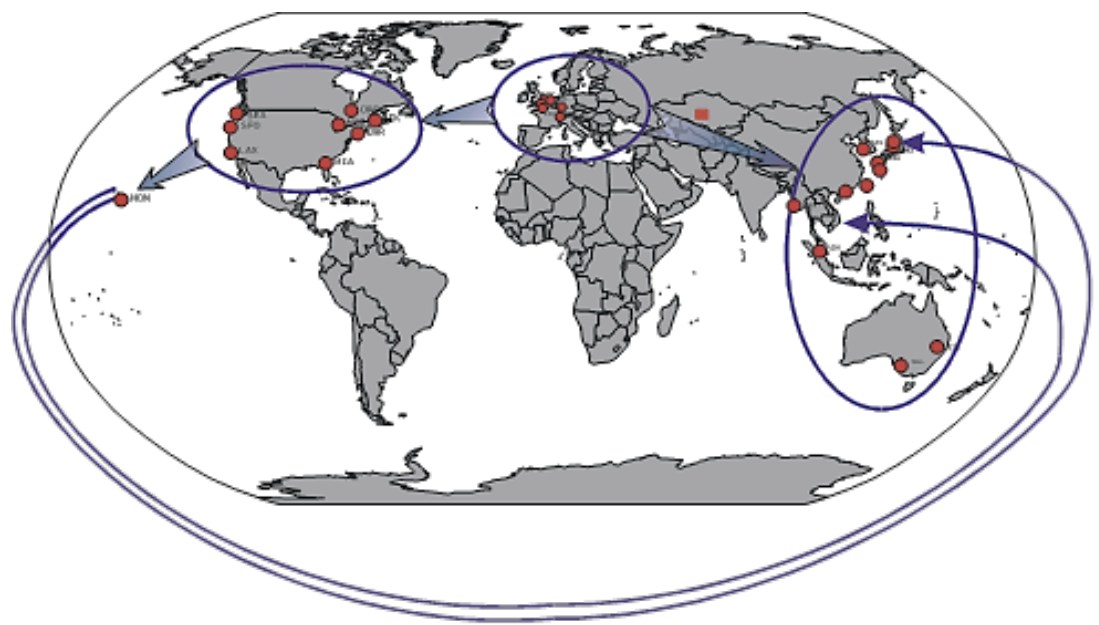

Figure 3. Map of Regular Flights Between Major Airports in the World

The distribution of large airports is characterised by the demographic factor. The European and North American regions are clearly expressed, but the countries of the Southeast Asia are of particular interest - these are countries from Japan to Australia. Figure 4 presents a map of regular flights of civil aviation for 2009, it can be seen that the zone of South America, Oceania and South Africa will begin to develop in the future. 


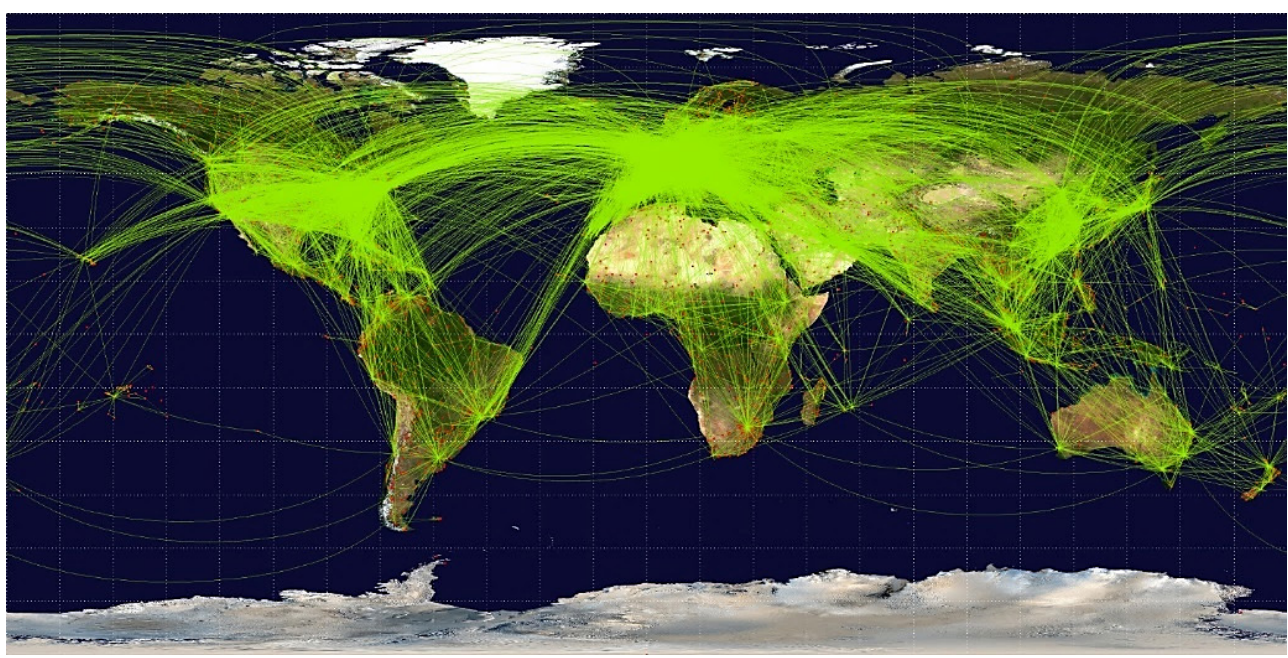

Figure 4. Civil Aviation Regular Flights Map, 2009

\section{Search for a Rational Aerodynamic Balancing Scheme of a Long-Range Aircraft}

Flight range analysis shows three distinct flight distances. The first one, up to $3000 \mathrm{~km}$, corresponds to inland flights. The second in the range from 8000 to 11000 is the transatlantic flight range. Historically, the $\mathrm{B} 747$ was designed for this range. The next frontier at 13.000 kilometres for the development of Asia-Pacific traffic from Europe and America. A-380 is a striking representative of this generation aircraft. The histogram has a subject area in a zone of 17.000 kilometres. These are the tasks of future generations - the so-called "kangaroo flights" - flights from Australia to Europe and America, for example, London - Sydney $(16.994 \mathrm{~km})$, or Melbourne $(16.903 \mathrm{~km})$, or Auckland $(18.338 \mathrm{~km})$.

Figure 5 shows a graphical representation of the mathematical model of the search for the rational appearance of the aerodynamic balancing scheme of a long-range aircraft in the plane of infrastructure terminal constraints. If we take the ordinate axis as the target load, and the abscissa axis as the flight range, then in the resulting minimax problem the load-range diagram is limited by the limiting flight range. It is necessary to find the vector of design parameters $X^{*}\left(x_{i}\right)$ on the set of parameters $X$ and restrictions $U$. If the range limitations are considered "hard", then it is enough to check the intersection points of the load-range diagram and the range restrictions for the feasibility of the project according to the aircraft existence equation.

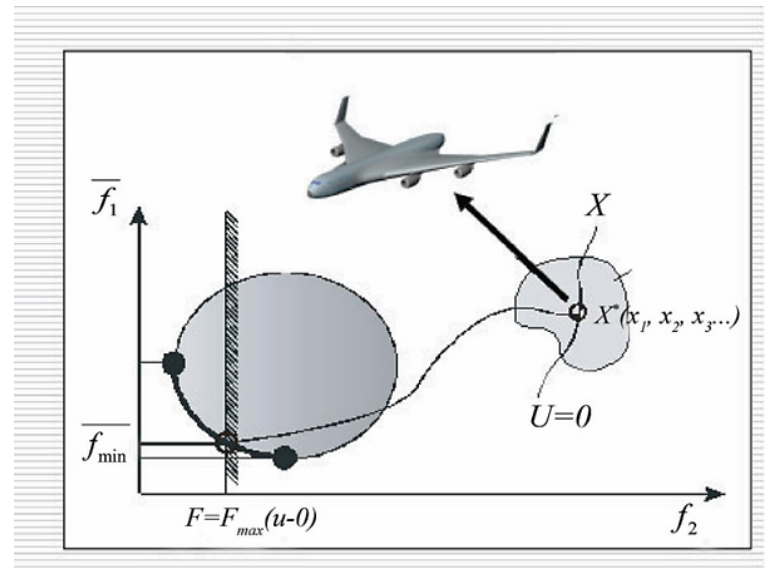

Figure 5. Graphic Search Model of the Rational Aerodynamic Shape of the Balancing Scheme of a Long-Range Aircraft in the Plane of Infrastructure Terminal Restrictions

In this case, the solution of the mass balance equation is defined by determining the mass of the aircraft and identifying groups of elements, the mass of which is known, as well as control over the mass ratio of individual units and systems of the aircraft according to the equation of mass balance of the aircraft (Eq. 2):

$$
1=\sum_{j} \overline{\mathrm{m}}_{\mathrm{j}}
$$

where: $\bar{m}_{j}-$ relative weight of the $j$-th element of the aircraft; $m_{a s}-$ weight of the airframe structure; $m_{e u}-$ weight of the engine unit; $\mathrm{m}_{\mathrm{ec}}$ - weight of equipment and control; $\mathrm{m}_{\mathrm{f}}-$ weight of the fuel; $\mathrm{m}_{\mathrm{tl}}-$ weight of a given target load; $\mathrm{m}_{\mathrm{sl}}$ - weight of service load and equipment.

Figure 6 shows the aircraft properties corresponding to these three characteristic flight ranges. It is noteworthy that all three aircrafts were designed for operation in the same aviation infrastructure, fly at the same speed with the same type of thrust systems in a four-engine scheme and use kerosene as fuel. 


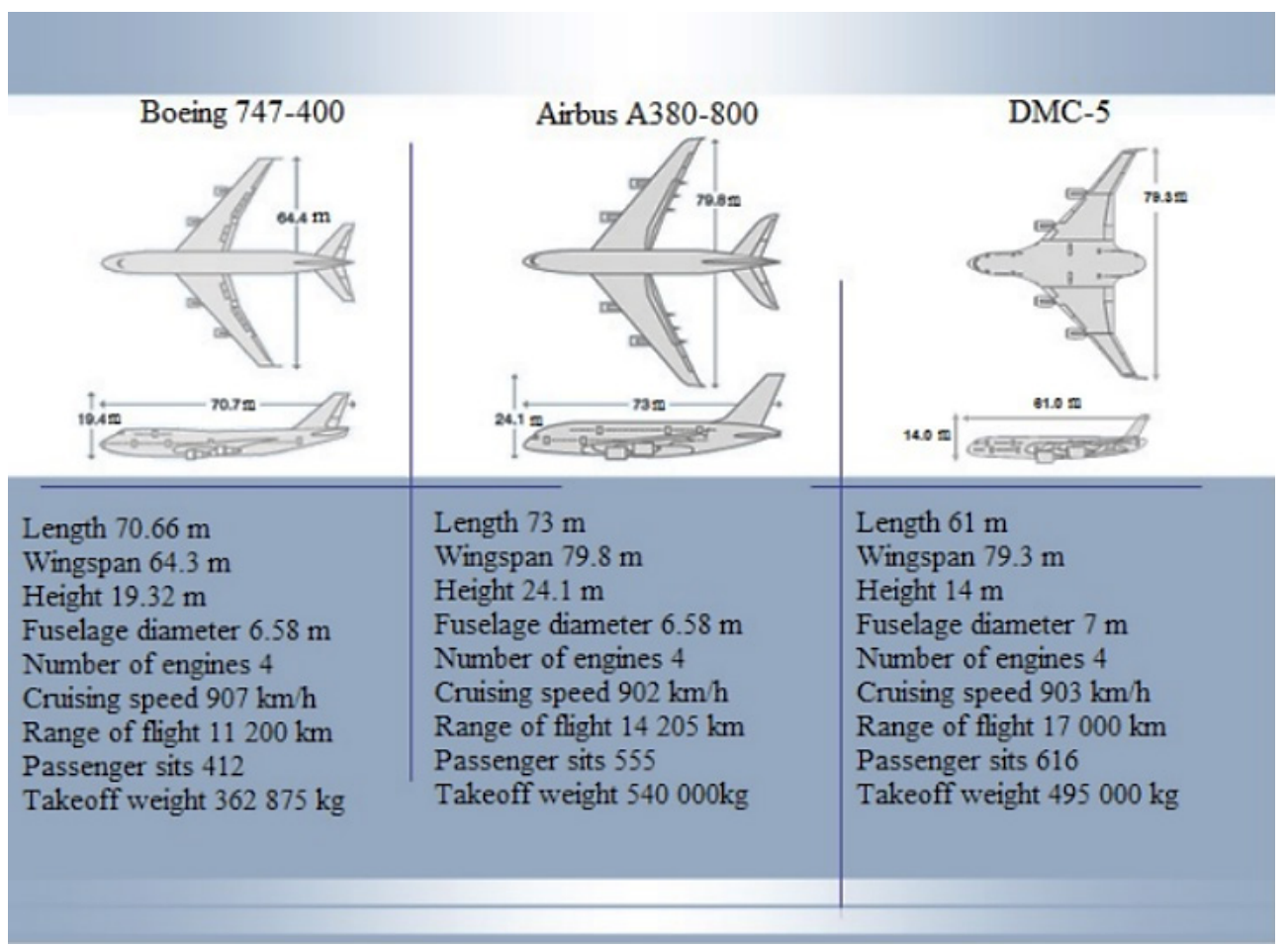

Figure 6. Long-Haul Passenger Aircraft

Among the long-haul flights, the most popular and massive flight is London - Sydney (16.994 km). Now it is performed with an intermediate landing. Since the days of Lord Sydney, this route has only grown in popularity. A successful experiment in the development of European civilization on one separate continent led to the flow of goods and passengers at a distance of $18.000 \mathrm{~km}$. After three hundred years, the travel length on this route was reduced to one day. The first successful attempt of a non-stop flight from London to Sydney was made by the Australian company Qantas in 1989, flying B747-400 $18.000 \mathrm{~km}$ in 20 hours 9 minutes without passengers and luggage. This is an example of point A on the load-range diagram.

These projects make it possible to perform the maximum possible flight ranges that, purely theoretically, can be carried out in the equatorial zone. For example, when flying from Buenos Aires to Shanghai, the range is 19.602 $\mathrm{km}$, from Auckland to Madrid - $19.628 \mathrm{~km}$, and between Taipei and Asuncion in the great circle $-19.918 \mathrm{~km}$. But so far there are no such tasks on the main lines. There are experiments and marketing exercises. On December 10, 2005, the Boing 777-200LR completed the longest flight from Hong Kong to London on a $21.602 \mathrm{~km}$ west-to-east flight in 22 hours 40 minutes. With a passenger capacity of 301 people, there were 27 people on board. This is a typical point A on the load-range diagram. Boing 777-200LR (Fig.
7) and take as a basis for the analysis of alternative ways to improve fatigue, comfort and ergonomics.

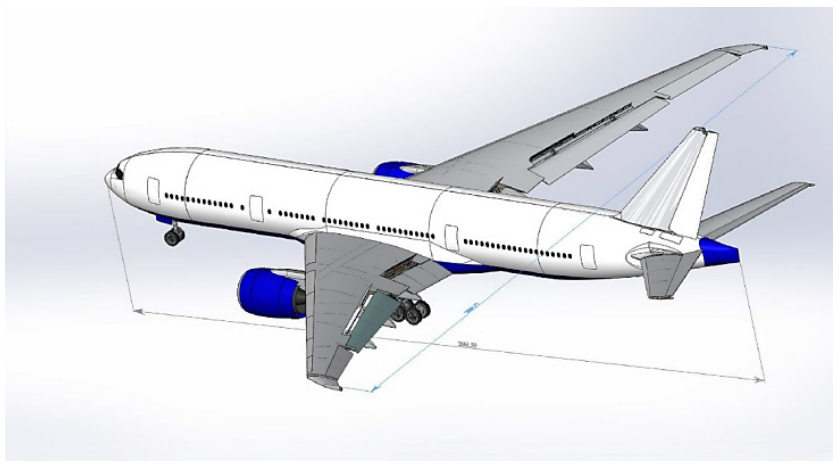

Figure 7. Boeing 777-200LR

The fatigue of passengers directly depends on the duration of the flight, which determines the presence of increased requirements for the comfort and ergonomics of the passenger seat with the increasing duration of the flight. Figures 8 and 9 show the graphs of the dependence of the step between the rows on the flight time in economy and business classes, respectively. Figure 10 shows the graph of the dependence of the aisle width on the flight time in economy and business classes. It can be noted that a qualitative leap in indicators occurs at around 7 hours 45 minutes. 


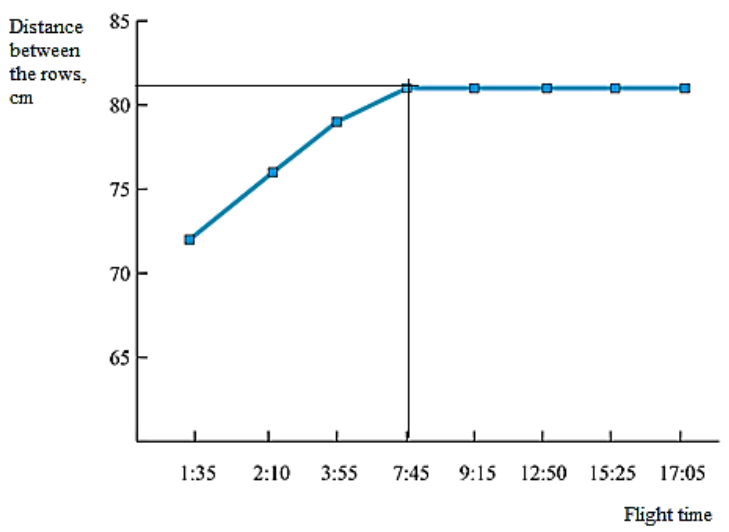

Figure 8. Graph of the Dependence of the Distance between the Rows on the Flight Time in Economy Class

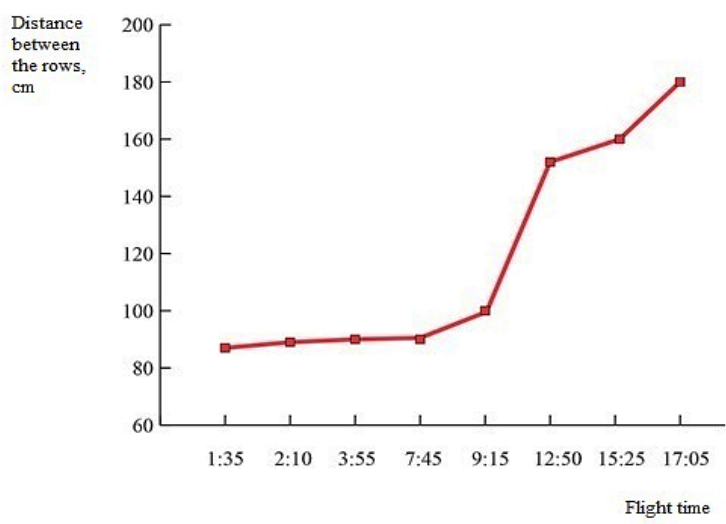

Figure 9. Graph of the Dependence of the Distance between the Rows on the Flight Time in Business Class

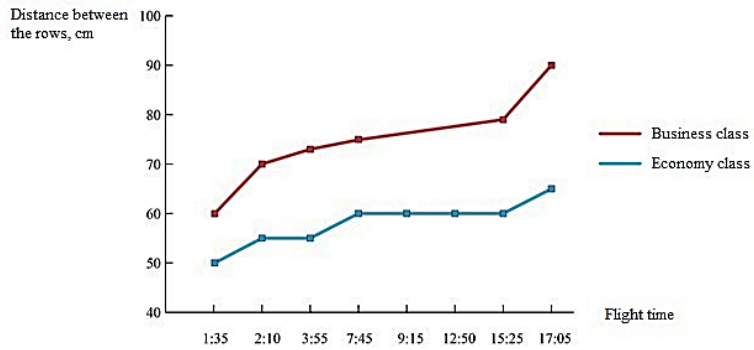

Figure 10. Graph of Aisle Width Versus Flight Time in Economy and Business Class

\section{Methods of Increasing the Comfort Levels in an Aircraft}

Many of the world's airlines offer alternatives to standard business or first-class seating to improve comfort. Such places are either wide folding chair-beds hidden by partitions, or separate compartment rooms with a full berth and other furniture. Also, these places are equipped with entertainment systems. Figure 11 shows a first-class compartment, Figure 12 shows the first-class seat equipped with a folding chair and partitions.

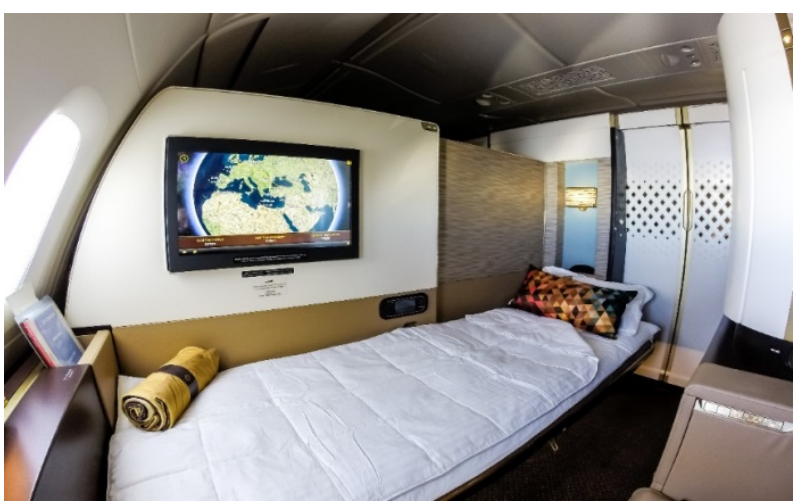

Figure 11. First Class Compartment

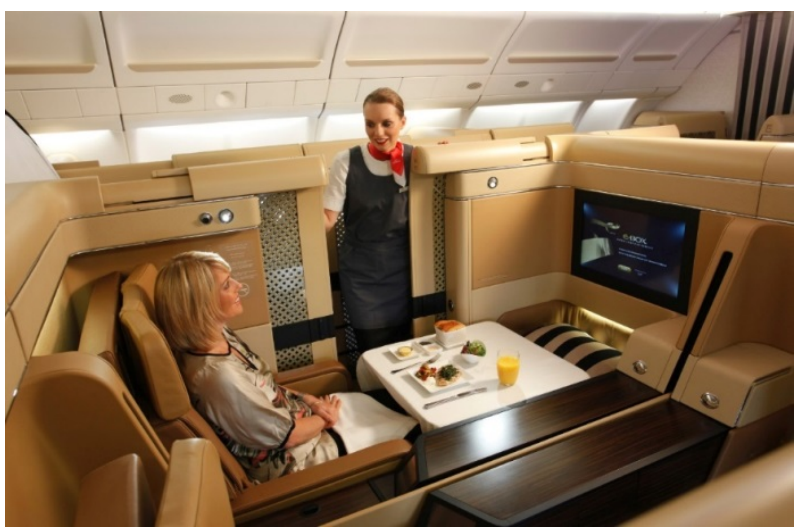

Figure 12. First Class Seat

Compartments for resting the aircraft crew are of particular interest. Rooms equipped with berths or comfortable armchairs are usually located in the voids below or above the main salon. In aviation, capsule accommodation is a promising alternative to traditional passenger accommodation. Not so long ago, the Air Lair capsule placement project by the British design agency Factorydesign was presented to the public. The capsule (Fig. 13) is a module with a folding chair, table and entertainment system. The modules are installed one above the other in two rows (Fig. 14), which allows increasing the passenger capacity in the area by up to $30 \%$.

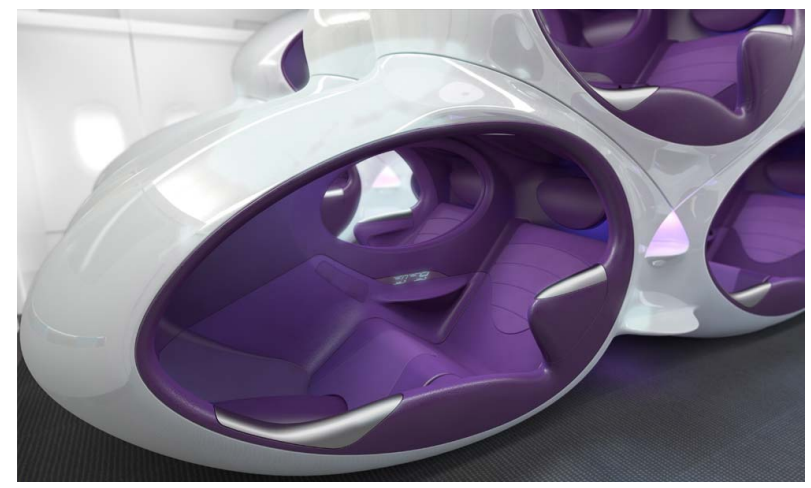

Figure 13. Air Lair Capsule 


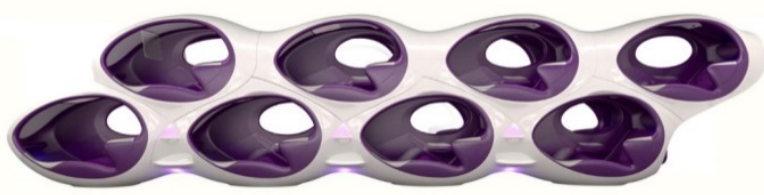

Figure 14. Air Lair Two-Story Capsule Layout

Table 1 shows the values of the area per person in the cabin with non-standard placement. Among the alternative types of arrangement, individual capsules in a two-story layout have the highest density of passengers. As a capsule placement on board the Boeing 777-200LR, a cell was proposed, shown in Figure 15. The chairs installed in the capsule fold out into a full-fledged berth. This cell provides the passenger with first-class convenience with the density of the business class layout. Figure 16 shows options for the layout of individual passenger cells on board of the Boeing 777-200LR.

Table 1. Values of Floor Space

\begin{tabular}{|c|c|}
\hline & Area, $\mathrm{m}^{2}$ \\
\hline Fenced-off first class seat & 1.55 \\
\hline First class compartment & 3 \\
\hline Crew lounge & 1.08 \\
\hline Capsule & 0.9 \\
\hline
\end{tabular}

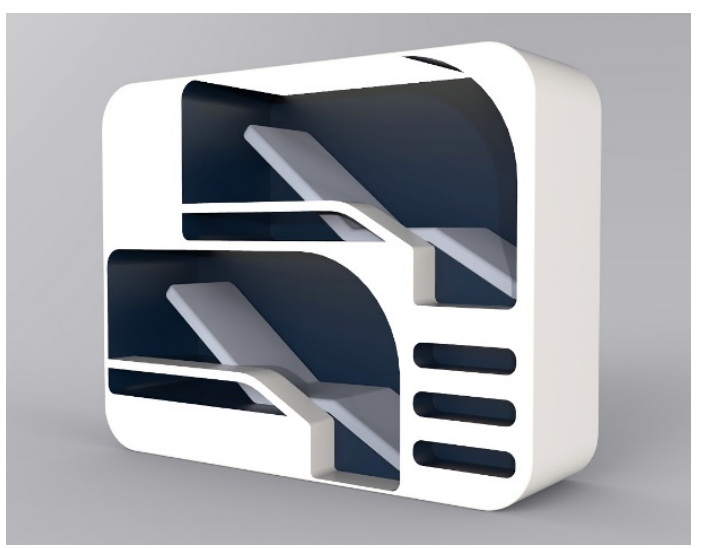

Figure 15. Individual Passenger Cell

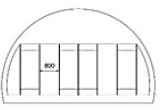

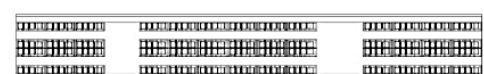

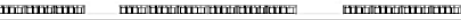

2
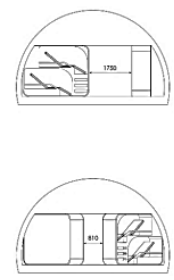

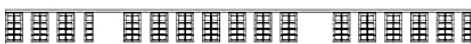

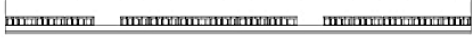

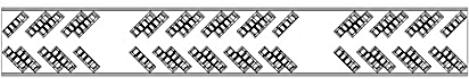

Figure 16. Layout Options for Passenger Cells

To assess the change in passenger capacity, the authors introduce the occupancy rate $K$, which is calculated as (Eq. 3):

$$
\mathrm{K}=\mathrm{N} / \mathrm{n} \text {, }
$$

where $N$-the number of passenger seats installed in a typical layout, $n$ - the number of passengers accommodated in cells on an equal area.

This coefficient shows how many times the cost of a ticket should be increased in comparison with the cost of a ticket of the corresponding class in order to recoup the flight. Table 2 shows the values of the $\mathrm{K}$ rate for business classes of Delta, Singapore Airlines and Emirates operated by Boeing 777-200LR. Table 3 shows the values of the occupancy rate K for the first class of the Emirates airlines.

Table 2. Values of the Occupancy rate K for Business Classes of Delta, Singapore Airlines and Emirates

\begin{tabular}{|c|c|c|c|c|c|}
\hline \multicolumn{2}{|c|}{ Layout type } & Number of cells & Number of passengers & \multicolumn{3}{c|}{ Coefficient K } \\
\hline \multicolumn{2}{|c|}{} & 104 & Delta & Singapore Airlines & Emirates \\
\hline 1 & 52 & 92 & 1.16 & 1.08 & 1.31 \\
\hline 2 & 46 & 84 & 1.32 & 1.3 & 1.5 \\
\hline 3 & 42 & 1.42 & 1.3 & 2.1 \\
\hline
\end{tabular}

Table 3. Values of the Occupancy Rate $\mathrm{K}$ for the First-Class of the Emirates Airlines

\begin{tabular}{|c|c|}
\hline Layout type & Coefficient K \\
\hline & Emirates \\
\hline 1 & 0.5 \\
\hline 2 & 0.67 \\
\hline 3 & 0.67 \\
\hline
\end{tabular}


Based on the given occupancy rates, it can be concluded that the most advantageous option is the layout with four rows of cells in the cross section. Figure 17 shows a side view of the passenger compartment, Figure 18 - a cross-section of the Boeing 777-200LR cabin and the layout of personal passenger cells.

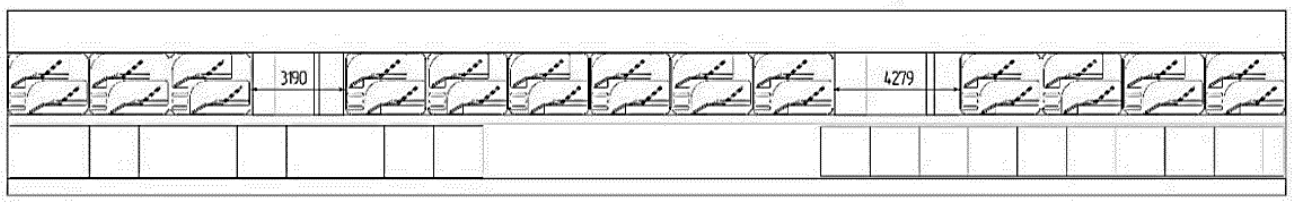

Figure 17. Side View of the Passenger Compartment

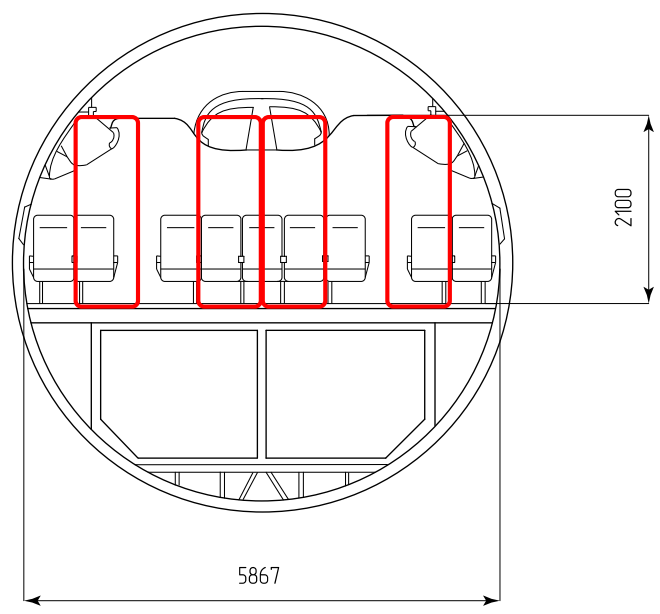

Figure 18. The Cross Section of Boeing 777-200LR and Layout of Individual Passenger Cells

The proposed variant of capsule placement, designed for the Boeing 777-200LR cabin, can be installed in other passenger airliners with a ceiling height of at least $2.1 \mathrm{~m}$. The installation of individual passenger cells in railway transport on the high-speed trains Strizh or Sobsan, in airport terminals as hotel accommodation also holds promises.

\section{Conclusions}

The aircraft has become a convenient method of transportation, which allows carrying out transport operations to any part of the world. The main idea of aviation in the 21 st century is the safety of passengers and crew while meeting the requirements for comfort. The structural-parametric analysis of the development of long-haul aircraft made it possible to form the concept of the fuselage layout with capsule accommodation of passengers.

The proposed variant of the capsule arrangement, designed for the Boeing 777-200LR cabin, can be installed in other passenger airliners with a ceiling height of at least $2.1 \mathrm{~m}$. Analysis of alternative options for the passenger compartment arrangements allows us to state:

- with a flight length of more than 8 hours, the flight is comfortable only in business or first classes;
- the proposed two-story capsule placement allows in a given cabin to provide the layout with first-class seats with the occupancy rate of 1.08 .

\section{Acknowledgments}

The work was carried out with the financial support of the state project of the Ministry of Education and Science on the topic "Theoretical and experimental research in production and processing of advanced metal and composite materials based on aluminum and titanium alloys" FSFF-2020-0017.

\section{REFERENCES}

[1] A.B. Avedian, M.Yu. Kuprikov, L.V. Markin. The Layout of Aircraft, MAI Press, Moscow, 2012.

[2] B.V. Boytsov, V.D. Borisov, N.M. Kiselev, V.G. Podkolzin. Life Cycle and Implementation of the Aircraft, MAI Publishing House, Moscow, 2005.

[3] N.A. Bulychev, E.L. Kuznetsova, V.V. Bodryshev, L.N. Rabinskiy. Nanotechnological aspects of temperature-dependent decomposition of polymer solutions. Nanoscience and Technology, An International Journal, 
Vol. 9, No. 2, 91-97, 2018.

[4] O.S. Dolgov, M.Yu. Kuprikov. Momento-Inertial Factor in the Formation of the Shape of the Aircraft, MAI-PRINT Publishing House, Moscow, 2008.

[5] O.S. Dolgov, M.Yu. Kuprikov, N.M. Kuprikov. Features of detecting the moment-inertial appearance of perspective aircraft, in the early stages of design, Bulletin of the Moscow Aviation Institute, Vol. 2, No. 17, 1-9, 2010.

[6] O.S. Dolgov, M.Yu. Kuprikov, A.V. Ripetsky. Features of geometric synthesis at different stages in the formation of the shape of a large passenger capacity aircraft, Bulletin of the Moscow Aviation Institute, Vol. 5, No. 17, 43-48, 2010.

[7] S.M. Eger, N.K. Lisejtsev, O.S. Samoilovich. Fundamentals of Automated Design of Aircraft, Mashinostroyeniye, Moscow, 1986.

[8] E.V. Egorov, A.D. Tuzov. Modeling Surfaces of Airborne Units, MAI, Moscow, 1988.

[9] E.V. Egorov, L.G. Nartova. Constructive Geometry, MAI, Moscow, 2012.

[10] V.F. Formalev, S.A. Kolesnik, E.L. Kuznetsova. Nonstationary heat transfer in anisotropic half-space under the conditions of heat exchange with the environment having a specified temperature, High Temperature, Vol. 54, No. 6, 824-830, 2016.

[11] V.F. Formalev, S.A. Kolesnik, E.L. Kuznetsova, L.N. Rabinskii. Heat and mass transfer in thermal protection composite materials upon high temperature loading, High Temperature, Vol. 54, No. 3, 390-396, 2016.

[12] V.F. Formalev, S.A. Kolesnik, E.L. Kuznetsova. Analytical study on heat transfer in anisotropic space with thermal conductivity tensor components depending on temperature, Periodico Tche Quimica, Vol. 15, No. 1, 426-432, 2018.

[13] V.F. Formalev, E.L. Kuznetsova, E.L. Kuznetsova. Mathematical modeling of the Stefan's problems with the determination of the coordinates and the velocities of the dynamically moving borders of phase transformations, Periodico Tche Quimica, Vol. 15, No. 1, 377-389, 2018.

[14] V.F. Formalev, S.A. Kolesnik. On inverse boundary heat-conduction problems for recovery of heat fluxes to anisotropic bodies with nonlinear heat-transfer characteristics, High Temperature, Vol. 55, No. 4, 564-569, 2017.

[15] V.F. Formalev, S.A. Kolesnik. On inverse coefficient heat-conduction problems on reconstruction of nonlinear components of the thermal-conductivity tensor of anisotropic bodies, Journal of Engineering Physics and Thermophysics, Vol. 90, No. 6, 1302-1309, 2017.

[16] A.M. Gorokhov, K.S. Zaikov, N.A. Kondratov, M.Yu. Kuprikov, N.M. Kuprikov, A.M. Tamickij. Analysis of scientific and educational space of the Arctic Zone of the Russian Federation and its contribution to social and economic development, European Journal of Contemporary Education, Vol. 7, No. 3, 485-497, 2018.

[17] S.A. Kolesnik, V.F. Formalev, E.L. Kuznetsova. On inverse boundary thermal conductivity problem of recovery of heat fluxes to the boundaries of anisotropic bodies, High Temperature, Vol. 53, No. 1, 68-72, 2015.

[18] M.Yu. Kuprikov, S.V. Maximov. Selecting rational parameters for the lift system of a subsonic transport plane, Ac Tch-96-24, Russian Sci-Tech, No. 1, 20-25, 1997.

[19] M.Yu. Kuprikov, S.V. Maximov. Using engine thrust excess to control aircraft flight and trimming, Ac Tch-96-23, Russian Sci-Tech, No. 1, 27-32, 1997.

[20] M.Yu. Kuprikov, S.V. Maksimov. Influence of infrastructure restrictions on the appearance of a long-distance aircraft, News of Universities "Aviation equipment", No. 1, 52-55, 1999.

[21] M.Yu. Kuprikov. Structural-Parametric Synthesis of the Geometric Shape of the Aircraft under Severe Constraints, MAI, Moscow, 2003.

[22] M.Yu. Kuprikov, A.G. Patrakov. Use of CAD/CAE systems in detecting the appearance of the main aircraft. Proceedings of the IX International Symposium "Dynamic and Technological Problems in Mechanics of Constructions and Continuous Media”, MAI, Moscow, 58-59, 2004.

[23] M.Yu. Kuprikov, L.N. Rabinskiy. Influence of infrastructure constraints on the geometrical layout of a long-distance aircraft, Journal of Mechanical Engineering Research and Developments, Vol. 4, No. 4, 40-45, 2018.

[24] M.Yu. Kuprikov, L.N. Rabinskiy. Vertical take-off and landing aircrafts: Myth or reality of modern aviation, Journal of Mechanical Engineering Research and Developments, Vol. 41, No. 4, 46-52, 2018.

[25] M.Yu. Kuprikov, L.N. Rabinskiy. Cross-polar routes as a factor that changed the geometric layout of long-distance aircrafts flying over long distances, Journal of Mechanical Engineering Research and Developments, Vol. 41, No. 4, 53-57, 2018.

[26] E.L. Kuznetsova, D.V. Leonenko, E.I. Starovoitov. Natural vibrations of three-layer circular cylindrical shells in an elastic medium, Mechanics of Solids, Vol. 50, No. 3, 359-366, 2015.

[27] V.V. Malchevsky. Automation of the Airplane Layout Process, MAI, Moscow, 1987.

[28] A.S. Okonechnikov, L.N. Rabinskiy, D.V. Tarlakovskii, G.V. Fedotenkov. A nonstationary dynamic problem on the effects of surface loads on a half-space with a nanosized structure within the framework of the cosserat medium model, International Journal of Nanomechanics Science and Technology, Vol. 7, No. 1, 61-75, 2016.

[29] M.V. Prokofiev, G.E. Vishnevskii, S.Y. Zhuravlev, L.N. Rabinskiy. Obtaining nanodispersed graphite preparation for coating ultrathin mineral fibers, International Journal of Nanomechanics Science and Technology, Vol. 7, No. 2, 97-105, 2016.

[30] K.S. Zaikov. The "Arctic competition" problem and the marine transport hubs: Is it a clash of business interests or the knockout game? Arctic and North, No. 19, 35-55, 2015. 